\title{
A misalignment-adaptive wireless power transfer system using PSO-based frequency tracking
}

\author{
Fuat Kılıç $^{a}$, Serkan Sezen ${ }^{b}$, Seyit Ahmet Sis ${ }^{c}$ \\ ${ }^{a}$ Department of Mechatronics Engineering, Faculty of Engineering, Ballkesir University, Ballkesir, Turkey \\ ${ }^{b}$ Department of Electrical \& Energy, Uzunçiftlik Nuh Çimento Vocational School, Kocaeli University, Kocaeli, Turkey \\ ${ }^{c}$ Department of Electrical \& Electronics Engineering, Faculty of Engineering, Ballkesir University, Balıkesir, Turkey \\ fuatkilic@balikesir.edu.tr,serkan.sezen@kocaeli.edu.tr,seyit.sis@balikesir.edu.tr
}

\section{ARTICLE INFO}

Article history:

Received: 19 February 2020

Accepted: 7 May 2020

Available Online: 19 June 2020

Keywords:

Frequency tracking

Frequency splitting

Particle swarm optimization

Adaptive wireless power transfer

AMS Classification 2010:

93C40, $93 E 25$

\begin{abstract}
One of the major challenges in inductive wireless power transfer (WPT) systems is that the optimal frequency of operation may shift predominantly due to coupling variation as a result of so-called frequency splitting phenomenon. When frequency splitting occurs, two additional resonance frequencies split from the coupler's resonance frequency. Maximum power levels are observed at these split resonance frequencies; however, these frequencies are strongly-dependent on the coupling coefficient, hence the distance and alignment between the couplers. In addition to that, peak power values at these frequencies can be different from each other due to small impedance differences between the primary and secondary side resonant couplers, forming a local and a global maximum. Therefore, the WPT system should adaptively operate at the correct frequency for achieving maximum power transfer. In this paper, a metaheuristic Particle Swarm Optimization (PSO) based frequency tracking algorithm is proposed for use in WPT systems. The WPT system employs multi sub-coil flux pipe couplers, a full-bridge inverter which is driven by TMS320F28069 controller card and is suitable for high power charging applications. The control algorithm can accurately find the global maximum power point in case of frequency splitting with asymmetric peaks. The proposed frequency tracking algorithm operates only at the primary side based on measurement of the input power level. Therefore, no additional communication link is needed between the primary and the secondary side. Effectiveness of the proposed control method is validated by performing experiments under three different misalignment scenarios and compared to the traditional Perturb and Observe algorithm.
\end{abstract}

\section{Introduction}

Magnetic coupling based wireless power transfer (WPT) systems have been comprehensively investigated in recent years. The WPT finds its use in various applications such as mobile electronic devices [1], electric vehicles (EVs) [2, 3], robots [4, 5] and medical devices $[6,7]$. Magnetically coupled coils, or so called couplers, are the major components in these systems determining the efficiency and power level delivered to the load. The WPT systems need to operate at one of the system's resonance frequencies for transferring the power in an efficient manner. However, temperature dependent variations in component values and load variations shift the resonance frequencies of the system. In this case, for guaranteeing maximum power delivery or maximum efficiency, a frequency tracking mechanism should be incorporated into the system.

Another important issue in WPT systems is so called frequency splitting phenomenon. Frequency splitting occurs when system operates at strongly coupled regime. In this regime, two more resonance frequencies emerge at lower and upper side of the isolated couplers' resonance frequency, making total of three resonance frequencies for the coupled system. The power values are maximum, same and independent of the coupling coefficient at these emerging split resonance frequencies; however, these frequencies are strongly- 
dependent on the coupling variations. Furthermore, any small difference between the isolated resonance frequencies of the primary and secondary coils results in different peak power and efficiency values at these frequencies. Hence, a local and a global maximum for the delivered power levels are observed. Operating the system at a global maximum is important for reducing charging time, utilizing electrical power efficiently, reducing the losses in power electronic components and reactive power. Therefore, the WPT system should adopt itself to achieve maximum power delivery when resonance frequencies shift due to coupling coefficient variations.

Numerous works have been reported on realizing adaptive WPT systems. In [8], an impedance matching network is utilized to maximize power transfer by compensating the efficiency reduction due to coupling variations. This method necessitates changing the position of coils, making the system less practical for the implementation. In $[9,10]$, authors again utilize matching circuits at both primary and secondary side; however, large number of passive elements increases the loss and the complexity of the system. In another work, zero crossing detector based phase angle is obtained by reading the voltage and current at the primary side to maximize the power transfer [11]. However, this method may become unstable if there is no resonance in the system. In another work [12], which is published by the authors of this manuscript, a fluxpipe coupler structure with three movable sub-coils is exploited for realizing an adaptive WPT system. The inductance value of the coupler is tuned by moving the position of the sub-coils to get back the system's resonance frequency shifted by the coupling variations. This solution, however, requires a complex mechanical mover and a dual side control [12].

In [13], authors propose a frequency tracking method based on simulated annealing algorithm for achieving maximum power transfer, but this algorithm is time inefficient and computationally dense [14]. Impedance matching and Perturb and Observe (PO) algorithm are implemented together in [15] for maximum power delivery to the load. In [16], power reduction due to resonance frequency shift caused by misalignment between primary and secondary coils is compensated by tracking the system's resonance frequency using again a PO algorithm. A drawback in PO algorithm, however, is that the algorithm may stuck at a local maximum rather than converging to the global maximum point. Ant Colony algorithm is also utilized for achieving maximum power transfer in [17]. Low converging speed and possibility of convergence to local maximum in large searching space are the main disadvantages in this algorithm [18]. In [19], derivation of power response is calculated and then the direction of frequency search is determined based on the sign of the derivation. As in PO algorithm, derivation method based algorithm may also stick to a local maximum rather than converging to the global maximum power point.
Particle Swarm Optimization (PSO) algorithm is another technique used in several adaptive WPT systems [20,21]. In [20], a software-defined, near-field WPT system is proposed where a particle swarm optimizer (PSO) is used to optimize the power transfer efficiency of the system. Matching network of the transmit and receive chain is controlled through the PSO algorithm to compensate for the efficiency reductions due to coupling variations [20]. However, the tuning range of the tunable components in matching circuits is limited and these components increase loss and complexity of the system. In [21], PSO algorithm is utilized in a frequency tracking controller to improve the power transfer efficiency of the WPT system. PSO algorithm's iterations are seems to be offline and does not consider the effect of dynamic variations on the system. In both [20] and [21], WPT systems operate in $\mathrm{MHz}$ range with a sinusoidal RF signal source and a power amplifier. $\mathrm{MHz}$ range WPT systems are not suitable for high power applications such as electric vehicle (EV) chargers.

In this paper, the Particle Swarm Optimization algorithm is implemented in a frequency tracking controller for use in misalignment adaptive WPT systems suitable for high power applications. The implemented frequency tracking system accurately finds the global maximum point without sticking to a local maximum under varying conditions. Therefore, the WPT system becomes insensitive to frequency splitting phenomenon caused by coupling variations. The algorithm needs only voltage and current measurement data at the resonant primary side coupler, making the proposed tracking system a simple primary side controller. The algorithm iteratively changes the switching frequency of the inverter. At each iteration, the controller calculates the power level at the input of the primary side resonant coupler. Iterations are online so that the algorithm does not stop and track the right frequency as long as the system is powered.

The paper is organized as follows: section 2 presents the frequency splitting phenomenon by analyzing a circuit model for a series-series (SS) compensated WPT system. Subsequently, PSO based frequency tracking algorithm is described in section 3. Finally, experimental setup and measurement results are presented in detail in section 4. Measurements are performed under three different scenarios with different misalignments and resonance conditions. For each scenario, a power vs frequency graph as an oscilloscope screenshot is obtained experimentally to show the frequency splitting phenomenon. Finally, accuracy of the PSO algorithm is proven by comparing the tracked frequency with the maximum power points shown in these graphs.

\section{WPT system and mathematical model for maximum power delivery}

In quite a few modern WPT applications (e.g electric vehicle chargers), separation between these primary 
and secondary side couplers needs to be large enough (loosely coupled) and the system should be suitable for lateral and vertical misalignments between the couplers to some extent. One needs to compensate for this loose coupling by connecting compensation capacitors to both primary and secondary side couplers. Except recently introduced hybrid compensation schemes, there are four basic compensation topologies: seriesseries (SS), series-parallel (SP), parallel-series (PS) and parallel-parallel (PP). In this work, voltage-source inverter is utilized as a high power source hence series compensation is chosen for the primary side. Parallel compensation at the secondary side results in a kdependent compensation capacitor at the primary side [24]. Therefore, series compensation scheme is chosen at the secondary side as well. Figure 1 shows a circuit model for a WPT system with an SS compensation topology. The components, $L_{1,2}$ and $R_{1,2}$ represent the self-inductances and loss resistances of the primary and secondary side couplers, respectively. $C_{1}$ and $C_{2}$ are the series connected compensation capacitors at primary and secondary sides, respectively. $V_{s}$ and $M$ are the RMS voltage level of the inverter and the mutual inductance between the couplers, respectively.

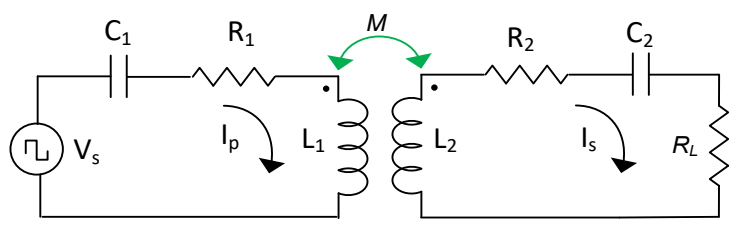

Figure 1. Circuit model for a WPT system with an SS compensation topology.

Analyzing the model in Figure 1 yields the following Eq. (1) for the power delivered to the load resistance, $R_{L}$, as function of source voltage $\left(V_{s}\right)$ and lumped components as follows [25]:

$$
P_{L}=\frac{\left(V_{s} \omega M\right)^{2} R_{L}}{a^{2}+b^{2}}
$$

where

$$
a=\left[\begin{array}{l}
R_{1}\left(\omega L_{2}-\frac{1}{\omega C_{2}}\right) \\
+\left(R_{2}+R_{L}\right)\left(\omega L_{1}-\frac{1}{\omega C_{1}}\right)
\end{array}\right]
$$

and

$$
\omega= \begin{cases}\omega_{0}=\frac{1}{\sqrt{L C}}, & \text { if } \omega M \leq R+R_{L} \\ \omega_{0}=\frac{1}{\sqrt{L C}} \text { and } \omega_{1}=\omega_{2}=\sqrt{\frac{C\left(R+R_{L}\right)^{2}-2 L \mp \sqrt{C\left(R+R_{L}\right)^{2}\left[C\left(R+R_{L}\right)^{2}-4 L\right]}+4 M^{2}}{2 C\left(M^{2}-L^{2}\right)}}, & \text { if } \omega M>R+R_{L}\end{cases}
$$


By plugging Eq. (4) into Eq. (1), the output power $\left(P_{L}\right)$ at $\omega_{0}, \omega_{1}$ and $\omega_{2}$ is simplified as follows:

$$
\begin{gathered}
P_{L}\left(\omega_{0}\right)=\frac{\left(V_{s} \omega M\right)^{2} R_{L}}{\left(R\left(R+R_{L}\right)+(\omega M)^{2}\right)^{2}} \\
P_{L}\left(\omega_{1,2}\right)=\frac{V_{s}^{2} R_{L}}{\left(2 R+R_{L}\right)^{2}}
\end{gathered}
$$

As seen in Eq. (5), the output power at $\omega_{0}$ is quite dependent on the mutual inductance $(M)$ between the couplers. That is, when a misalignment occurs between the primary and secondary side couplers, or the distance between them changes, $P_{L}$ also changes. One needs to vary the inverter's voltage level to stabilize output power against varying coupling level. However, if system operates at the other resonance frequencies, $\omega_{1}$ or $\omega_{2}$, the output power is independent of $M$ (as given in Eq. (6)), making the system insensitive to the coupling variations.

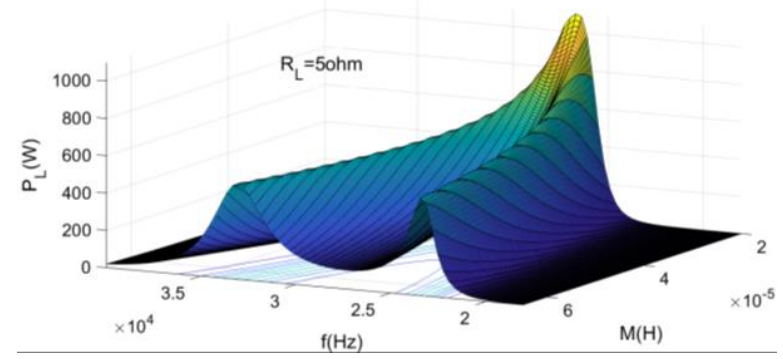

a) Sub-figure 1 .

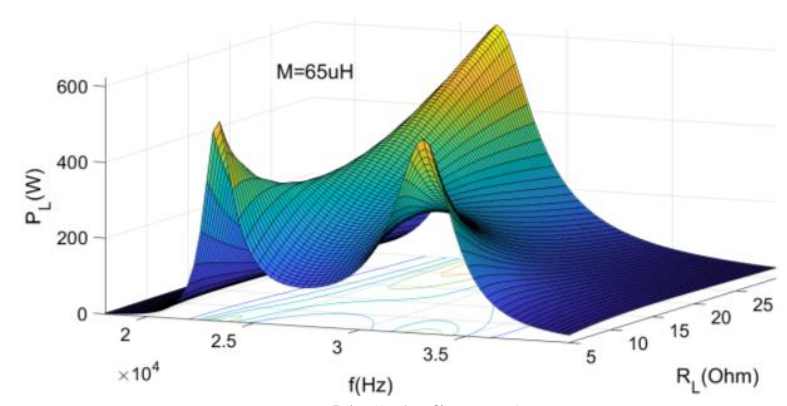

b) Sub-figure 2 .

Figure 2. Output power's (PL's) variation as a function of $\mathrm{f}-\mathrm{M}$ (a), and f-RL (b)

It should be remembered that the $\omega_{1}$ or $\omega_{2}$ exist only at the strongly coupled regime and their values are dependent on $M$ when the second condition in Eq. (4) is satisfied. Figure 2 shows simulated output power $\left(P_{L}\right)$ using Eq. (1) as a function of $f$ and $M$. Frequency splitting phenomenon is clearly observed in Figure 2. As seen in these graphs, any variation of $\mathrm{M}$ and $R_{L}$ significantly changes the output power transferred to the load. Therefore, for a large power delivery to the load, system's frequency should be tuned to either $\omega_{1}$ or $\omega_{2}$ by applying a frequency tracking algorithm.

\section{PSO based frequency tracking algorithm}

\subsection{Basics of PSO Algorithm}

Particle Swarm Optimization (PSO) algorithm is inspired from the behaviors of swarm animals such as birds and fishes. Each individual animal in the swarm is called as particle and have the potential of exhibiting a solution to the problem to be solved. The particle looks for the best location in a three dimensional (3D) space [26]. A major advantage of PSO is its easier applicability to various different applications such as power systems, thermodynamics, image processing, proportional-integral-derivative (PID) control and machine learning as compared to other algorithms [27, 28]. PSO algorithm has several topologies and one of the most utilized topologies is a so called Von Neumann topology. In this topology, the particles are connected to one another in such a way that they communicate with each other from one point to the opposite point in a square pattern [29]. As in other topologies, Von Neumann topology based PSO algorithm is established on two principles; learning the previous knowledge and providing communication between the particles in the swarm. The Von Neumann topology consists of $N$ element particles in a $D$ dimensional space [30]. Each particle should achieve the best performance and all the particles should move towards the particle with the best performance [31]. Each particle has its own speed, and this speed is updated based on previous performance of the particle and the swarm. The algorithm initially produces random solutions and recursively update the locations of particles and search for the global maximum within the search space. By evaluating each individual particle, the best performance $\left(P_{\text {best }}\right)$ and the particle associated with the best performance are stored in the memory. The inputs of the algorithm are varied until some of the goals are satisfied.

\subsection{The application of PSO algorithm to frequency tracking in a WPT System}

Figure 3 shows the vectorial movement of frequencybased particles in the PSO algorithm. The direction of particles depends on the best frequency per particle, the frequency at which maximum power is achieved in the whole swarm, previous frequency, current frequency and up-to-date frequency. Figure 4 shows algorithm's flow chart for frequency tracking to maximum power. This flow chart is elaborated under four main steps as follows:

Step I (Start): In this first step, optimization is launched by establishing an initial population. A frequency solution vector with $\mathrm{Np}$ elements is setup as given in Eq. (7). The initial vector is built on randomly chosen frequencies. The constants, $\gamma 1$ and $\gamma 2$, given in Eq. (8) and (9) are then determined based on $c_{1}$ and $c_{2}$ which satisfy the conditions given in Eq. (10) and (11). 


$$
\begin{gathered}
f_{r}=\left[f_{r 1}, f_{r 2}, f_{r 3}, \ldots, f_{r n}\right], n=1,2,3, \ldots, N_{p} \\
\gamma_{1}=r_{1} c_{1} \\
\gamma_{2}=r_{2} c_{2} \\
c_{1}+c_{2}<4 \\
\phi>0.5\left(c_{1}+c_{2}\right)-1
\end{gathered}
$$

$\emptyset$ is a random variable of which values is limited to the 0-0.5 range. Similarly, $r_{1}$ and $r_{2}$ are also random variables limited to $0-1$ range. The $c_{1}$ and $c_{2}$ are cognitive and social coefficients ranging between 0 and 2. The values of the aforementioned constants are utilized to update the frequency and power values in the next step.

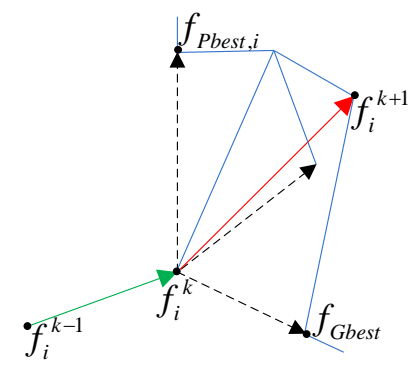

Figure 3. The vectorial movement of frequency-based particles in the PSO algorithm

The best individual particle frequency $\left(f_{p b e s t, r}\right)$ and the best global frequency $\left(f_{\text {Gbest }}\right)$ value within the whole swarm are randomly chosen as follows:

$$
\begin{gathered}
f_{\text {Pbest }, r}=\left[f_{\text {Pbest } 1}, f_{\text {Pbest } 2}, f_{\text {Pbest } 3} \ldots f_{\text {Pbest } N}\right], \\
n=1,2,3, \ldots, N_{p} \\
f_{\text {Gbest }}=[0-1]
\end{gathered}
$$

The $f_{w p t}, f_{a c t}, P_{w p t}$, and $P_{a c t}$ variables shown in the flow chart are the stored frequency, up-to-date frequency, calculated power and up-to-date power, respectively.

Step II (Acquiring Measurement Data): Current and voltage values at the input of the WPT system are measured using hall effect based sensors as will be discussed in the next section. These measured data are acquired into the microcontroller and utilized as an input to the microcontroller. Subsequently, the power is calculated using measured voltage and current data. Once the condition in Eq. (14) is satisfied, the algorithm utilizes the best individual particle location to update the frequency as given in Eq. (15).

$$
f_{i, j}>f_{\text {Pbest_i }}
$$

$$
f_{\text {Pbest }-i}=f_{i, j}
$$

From the start of the algorithm, the best frequency $\left(f_{\text {Pbest }}\right)$ for $j_{\text {th }}$ iteration and $i_{\text {th }}$ particle is stored in the memory. The best global frequency is also stored in the memory as $f_{\text {Gbest. }}$.

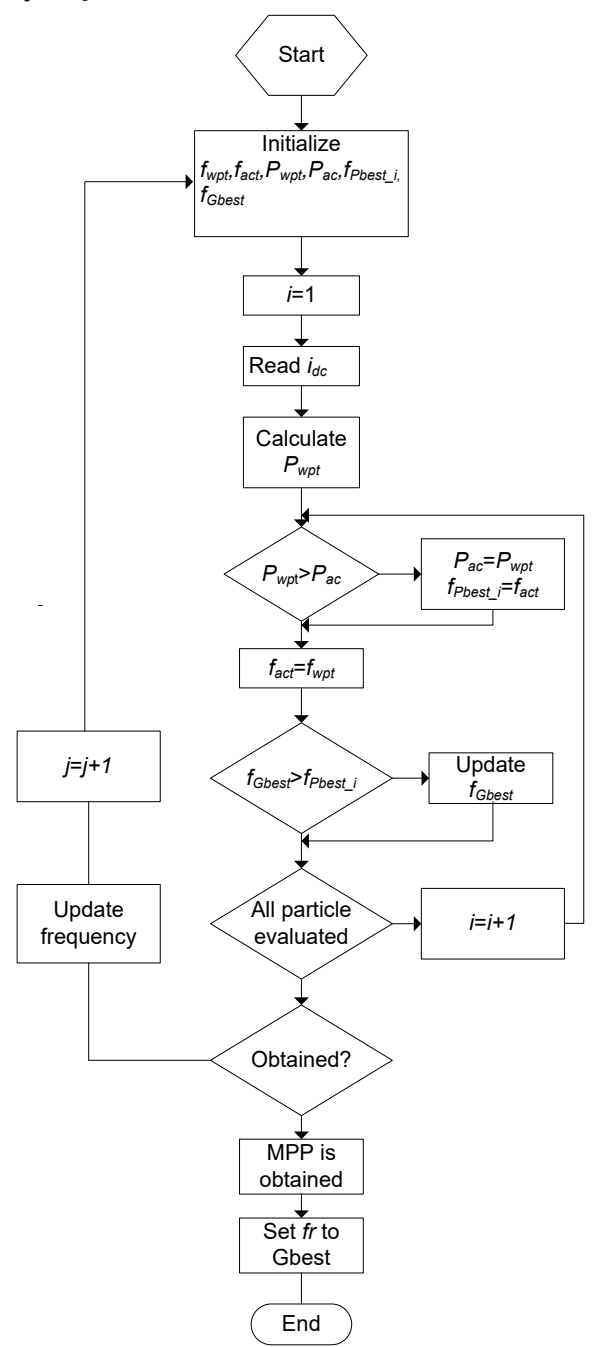

Figure 4. The flow chart for PSO based frequency tracking algorithm

Step III (Updating the Frequency Values): The stored $f_{\text {Pbest }}$ and $f_{\text {Gbest }}$ are plugged in to updated frequency expression as follows:

$$
\begin{gathered}
f_{i, j}(t+1)=f_{i, j}(t)+\delta_{i, j}(t+1) \\
\delta_{i, j}(t+1)=\phi \delta_{i, j}(t)+\gamma_{1}\left(f_{\text {Pbest }_{i}}-f_{i, j}(t)\right) \\
+\gamma_{2}\left(f_{\text {Gbest }}-f_{i, j}(t)\right)
\end{gathered}
$$

The $i, t, f_{i, j}, f_{i, j}(t+1)$ and $\delta_{i, j}(t+1)$ are particle number, iteration number, current particle frequency, updated particle frequency and updated correction term.

Step IV (Checking the Maximum and Minimum Boundary Values): The maximum and minimum boundary values of updated frequencies are checked. If the boundary values are exceeded, higher and lower values, respectively, are taken into the program. According to flow chart, once initial values are 
assigned, initial frequency value is sent to pulse width modulation (PWM) unit and then time based period is formed. The full-bridge inverter is driven by $50 \%$ duty cycled PWM signal at a given frequency. The algorithm is run real-time and the frequency is recursively updated until it converges to the frequency at which power is maximized. The frequency range over which the algorithm make searching is from 10 $\mathrm{kHz}$ to $40 \mathrm{kHz}$.

\section{Experimental setup and measurement results}

An experimental WPT system is setup using a DC to $\mathrm{AC}$ high frequency inverter, flux-pipe couplers, seriesconnected capacitors and a heater load resistance $\left(R_{L}\right)$. Figure 5 (a) and (b) show the block diagram and photo of experimental setup of the implemented WPT system, respectively. The experimental setup employs a microcontroller, gate-drive circuit, protection circuit and IGBT switches. The microcontroller is Texas Instruments' TMS320F28069 card and can be programmed via Matlab/Simulink. HCPL-3120 optocoupler is utilized for driving the IGBTs with signals from microcontroller. Isolation between power and driver circuit is ensured by MURATA's MGJ2 series DC/DC converter. The dead time between the two switching signals of IGBTs on the same branch is set as $2 \mu \mathrm{s}$ in the program. Currents are measured through hall-effect based LEM LA25-P and LEM LV25-P current and voltage sensors. The four IGBTs, in the inverter stage, are IXYS's hyper fast IXGH40N60B2D1 transistors.

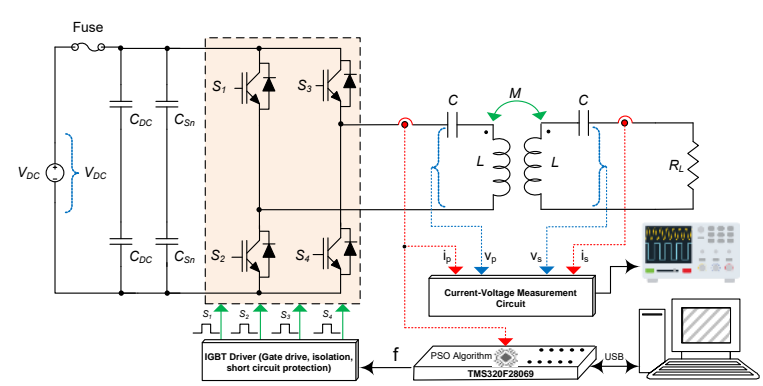

a) Sub-figure 1 .

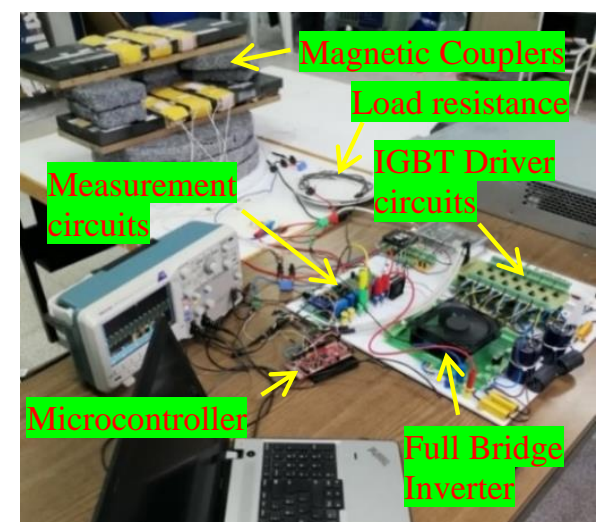

b) Sub-figure 2 .

Figure 5. Block diagram (a) and photo of experimental WPT system (b)
Two series connected $2200 \mu \mathrm{F} / 450 \mathrm{~V}$ DC capacitors and a $1 \mu \mathrm{F} / 1200 \mathrm{~V}$ snubber capacitor, which is parallel to these two $2200 \mu \mathrm{F}$ capacitors, are utilized at the DC bus node. The flux-pipe coupler utilized in this experiment is basically a helical structure with three sub-coils wound around a common ferrite core (Figure 5 (b)). The detailed simulation and measurement results of this coupler structure are out of scope of this paper and are reported elsewhere [12]. The list of component values and other details for the experimental setup are shown Table 1.

The proposed frequency tracking method is experimentally verified under three scenarios. In the first scenario, the couplers are perfectly aligned and separated with $100 \mathrm{~mm}$ vertical gap $(d z=100 \mathrm{~mm})$. In the second scenario, the coupling coefficient between couplers is reduced by applying a $150 \mathrm{~mm}$ lateral misalignment along the coupler's longer side $(d y=150$ $\mathrm{mm})$. In the third scenario, the sub-coil separation $\left(d_{s u b}\right)$, which is originally $60 \mathrm{~mm}$ for each coupler, is changed in secondary side coupler until the selfinductance of the secondary side coupler increases to $185 \mu \mathrm{H}$ from its original value of $170 \mu \mathrm{H}$. This final scenario results in moving the maximum power point from lower resonance frequency to the higher one. The difference between the power levels becomes also larger in this last scenario. A PO algorithm is also run in the last scenario and compared to the PSO algorithm. All three scenarios are sketched in Figure 6 and are summarized in Table 2.

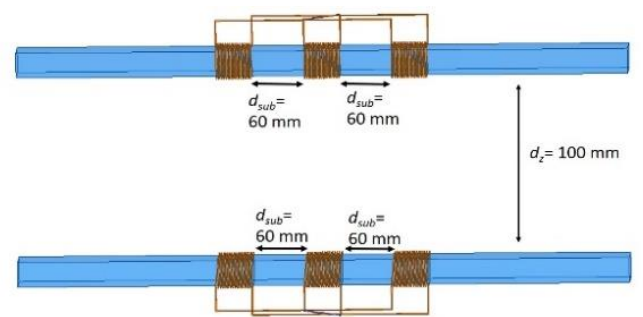

a) Scenario 1

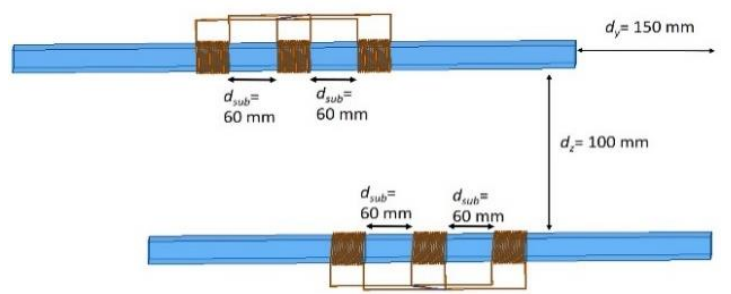

b) Scenario 2

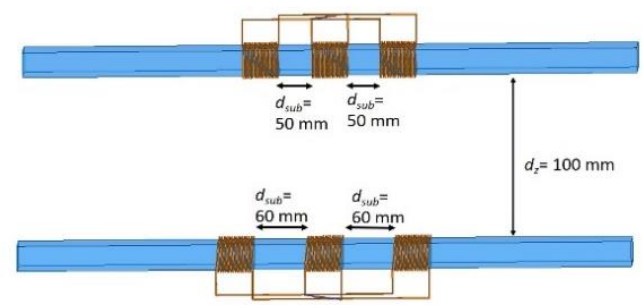

c) Scenario 3

Figure 6. Three expermental scenarios with various coil and sub-coil orientations. 
Table 1: Component values and other details of experimental setup

\begin{tabular}{lcc}
\hline Symbol & Parameter & Value \\
\hline$V_{D C}$ & DC rail voltage & $50 \mathrm{~V}$ \\
$C_{D C}$ & DC rail capacitors & $2 \times 2200 \mu \mathrm{F}$ \\
& magnetic induction \\
$C_{S n}$ & $\begin{array}{c}\text { DC rail snubber } \\
\text { capacitors }\end{array}$ & $2 \times 1 \mu \mathrm{F}$ \\
& Load resistance & $5 \Omega$ \\
$R_{L}$ & $\quad$ Coupler \\
$L_{l}=L_{2}$ & inductances & $170 \mu \mathrm{H}$ \\
$M$ & Mutual inductance & $64,75 \mu \mathrm{H}$ \\
$C_{l}=C_{2}$ & Compensation & $175 \mathrm{nF}$ \\
& capacitors \\
$R_{l}=R_{2}$ & Loss resistances & $10 \mathrm{~m} \Omega$ \\
\hline
\end{tabular}

Table 2: Details of experimental scenarios

\begin{tabular}{|c|c|c|c|}
\hline State & $\begin{array}{c}\text { Scenario } \\
1\end{array}$ & $\begin{array}{l}\text { Scenario } \\
2\end{array}$ & $\begin{array}{c}\text { Scenario } \\
3\end{array}$ \\
\hline $\begin{array}{l}\text { Vertical } \\
\text { separation }(d z)\end{array}$ & $100 \mathrm{~mm}$ & $100 \mathrm{~mm}$ & $100 \mathrm{~mm}$ \\
\hline $\begin{array}{l}\text { Lateral } \\
\text { misalignment }(d y)\end{array}$ & $0 \mathrm{~mm}$ & $150 \mathrm{~mm}$ & $0 \mathrm{~mm}$ \\
\hline Separation & P.S. $=60$ & P.S. $=60$ & P.S. $=60$ \\
\hline $\begin{array}{l}\text { between sub-coils } \\
\left(d_{\text {sub }}\right)\end{array}$ & $\begin{array}{c}\text { S.S. }=60 \\
\mathrm{~mm}\end{array}$ & $\begin{array}{c}\text { S.S. }=60 \\
\mathrm{~mm}\end{array}$ & $\begin{array}{c}\text { S.S. }=50 \\
\mathrm{~mm}\end{array}$ \\
\hline $\begin{array}{l}\text { Primary coupler } \\
\text { self-inductance } \\
\left(L_{l}\right)\end{array}$ & $170 \mu \mathrm{H}$ & $170 \mu \mathrm{H}$ & $170 \mu \mathrm{H}$ \\
\hline $\begin{array}{l}\text { Secondary } \\
\text { coupler self- } \\
\text { inductance }\left(L_{2}\right)\end{array}$ & $170 \mu \mathrm{H}$ & $170 \mu \mathrm{H}$ & $185 \mu \mathrm{H}$ \\
\hline $\begin{array}{l}\text { Mutual- } \\
\text { inductance }(M)\end{array}$ & $65 \mu \mathrm{H}$ & $50 \mu \mathrm{H}$ & $64 \mu \mathrm{H}$ \\
\hline
\end{tabular}

(P.S.=Primary Side, S.S.=Secondary Side)

\subsection{Scenario I}

In scenario I, the couplers are perfectly aligned and separated with $100 \mathrm{~mm}$ vertical gap $(\mathrm{dz}=100 \mathrm{~mm})$. Before running PSO based frequency tracking algorithm, input power to the primary side resonant coupler and the inverter's switching frequency are scanned simultaneously in time to make sure that the system exhibits frequency splitting phenomenon. The switching frequency of the inverter is linearly increased from $10 \mathrm{kHz}$ to $40 \mathrm{kHz}$ with approximately $100 \mathrm{~Hz}$ increase at each time step. Figure 7 (a) shows oscilloscope screenshot of this scan. The data shown with cyan-colored line is the scanned input power and exhibits two peaks at approximately $24 \mathrm{kHz}$ and 33 $\mathrm{kHz}$, respectively. The data with maize-colored line is the scanned frequency. The PSO based frequency tracking algorithm is then utilized in microcontroller to drive the gates of IGBTs. Figure 7 (b) shows the oscilloscope screenshot of the PSO algorithm's performance for tracking the frequency of maximum power. In this graph (Figure 7 (b)), the instantaneous frequency searched by the PSO algorithm and the corresponding input current are shown with maize and cyan colored lines, respectively.

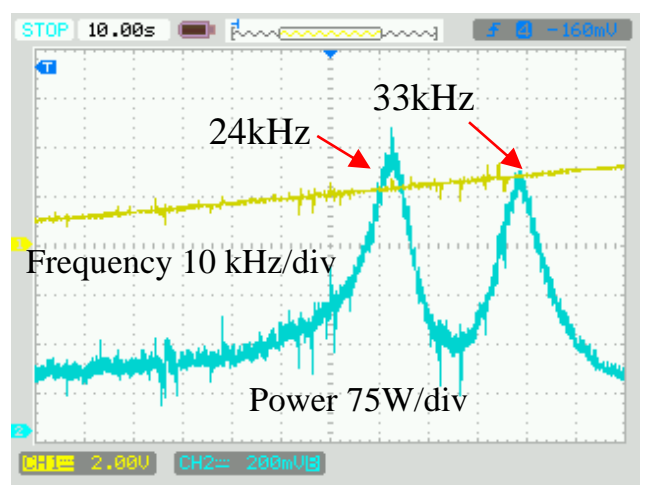

a) Sub-figure 1 .

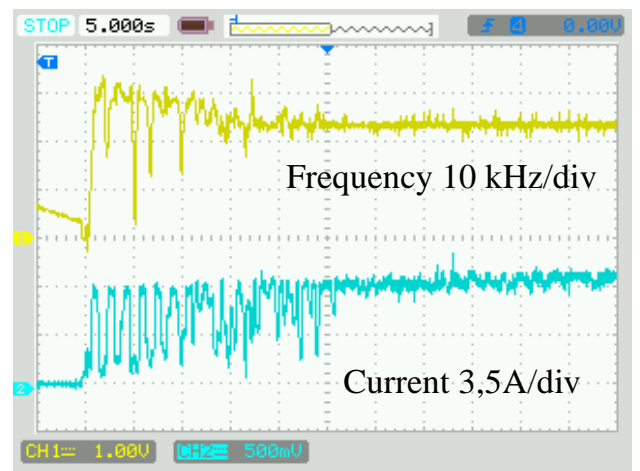

b) Sub-figure 2 .

Figure 7. Oscilloscope screenshot for Scenario I for (a) scanning for input power to the primary side resonant coupler and the inverter's switching frequency and (b) performance of PSO algorithm

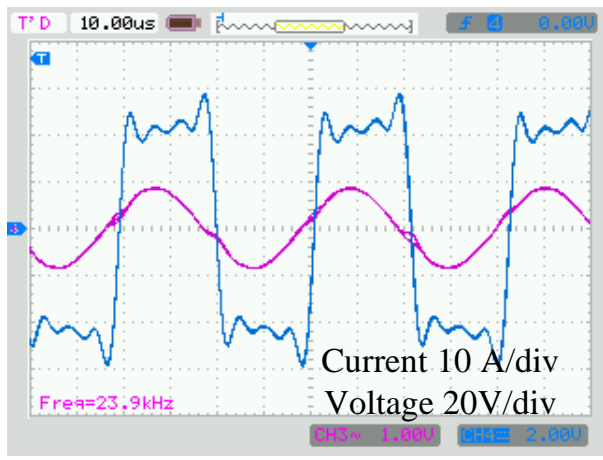

a) Sub-figure 1 .

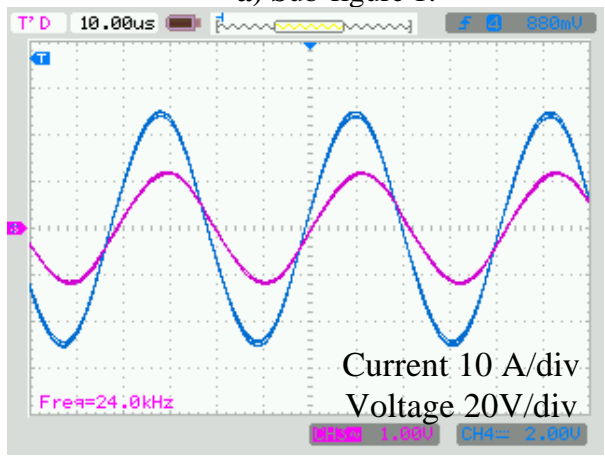

b) Sub-figure 2 .

Figure 8. For $50 \mathrm{~V}$ DC bus voltage and $24 \mathrm{kHz}$ switching frequency voltage (blue) and current (purple) at the (a) input and (b) load resistance $\left(R_{L}\right)$. 
One can read the searched frequency and input current level as well as the time using given $\mathrm{kHz} / \mathrm{div}, \mathrm{A} / \mathrm{div}$ and s/div (on the top left of the graph) scales on the graphs. As seen in Figure 7 (b), the PSO algorithm finds the resonance frequency for maximum power as $24 \mathrm{kHz}$ in approximately 25 seconds. The tracked $24 \mathrm{kHz}$ agrees with the initial scanning results shown in Figure 7 (a), verifying the accuracy of PSO algorithm. The measured voltage and currents at the input and at the load resistance $\left(R_{L}\right)$, when inverter operates at tracked 24 $\mathrm{kHz}$, are shown as oscilloscope screenshots in Figure 8.

\subsection{Scenario II}

In this scenario, the coupling coefficient between couplers is reduced by applying a $150 \mathrm{~mm}$ lateral misalignment along the coupler's longer side $(d y=150$ $\mathrm{mm}$ ). As in scenario 1, first, input power to the primary side resonant coupler and the inverter's switching frequency are scanned simultaneously in time. Figure 9 (a) shows oscilloscope screenshot of this scan. The data shown with cyan-colored line is the scanned input power and exhibits two peaks at approximately 25.5 $\mathrm{kHz}$ and $31.5 \mathrm{kHz}$, respectively. The data with maizecolored line is the scanned frequency.

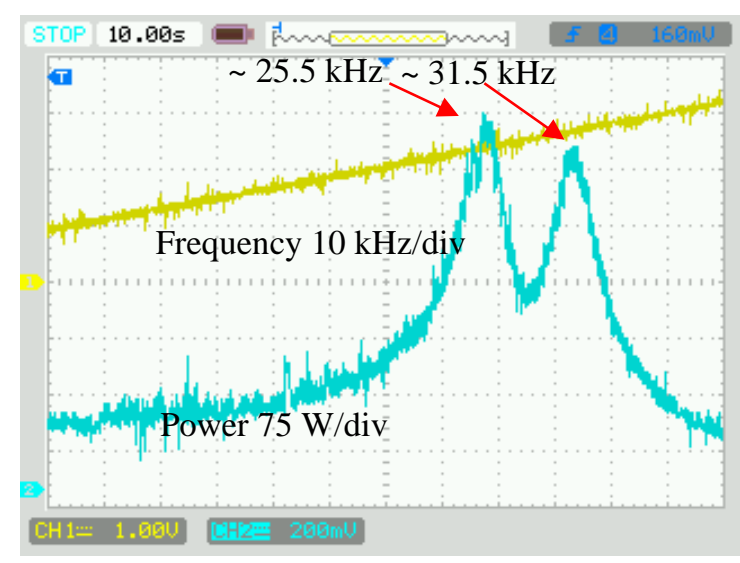

a) Sub-figure 1 .

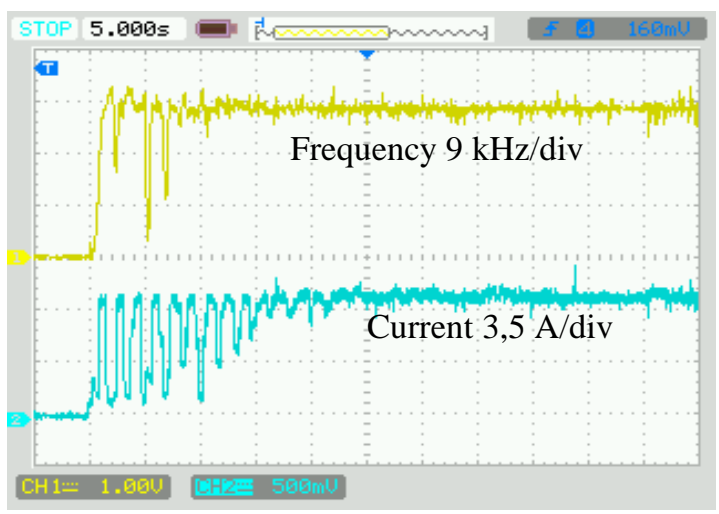

b) Sub-figure 2 .

Figure 9. Oscilloscope screenshot for Scenario II for scanning for input power to the primary side resonant coupler (a) and the inverter's switching frequency and performance of PSO algorithm (b)

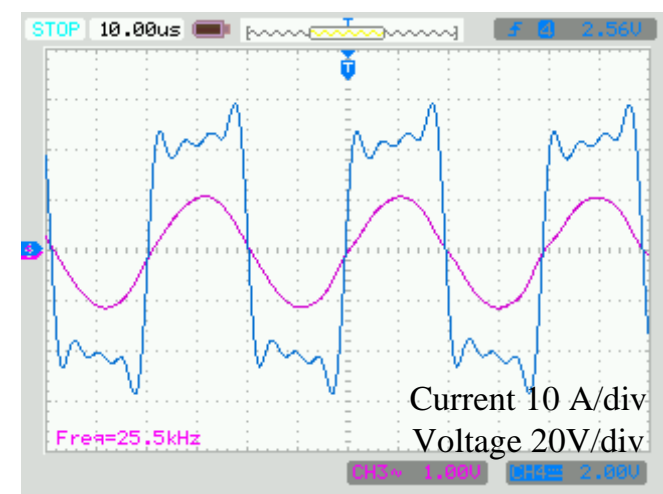

a) Sub-figure 1 .

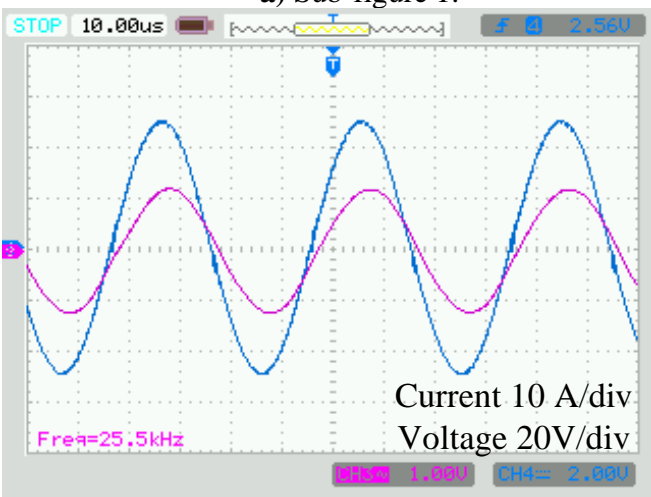

b) Sub-figure 2 .

Figure 10. For $50 \mathrm{~V}$ DC bus voltage and $25.5 \mathrm{kHz}$ switching frequency voltage (blue) and current (purple) at the input (a) and load resistance $\left(R_{L}\right)(\mathrm{b})$.

As seen in Figure 9 (a), the resonance frequencies approach to one another when $150 \mathrm{~mm}$ misalignment is applied along the longer side of the couplers. This change in the resonance frequencies can be attributed to the decrease in the mutual inductance between the couplers. Figure 9 (b) shows the oscilloscope screenshot of the PSO algorithm's performance for tracking the frequency of maximum power. In this graph, the instantaneous frequency searched by the PSO algorithm and the corresponding input current are shown with maize and cyan colored lines, respectively. The PSO algorithm finds the resonance frequency for maximum power as $25.5 \mathrm{kHz}$ in approximately 15 seconds. The tracked $25.5 \mathrm{kHz}$ agrees with the frequency of global maximum power shown in Figure 9 (a)), verifying the accuracy of PSO algorithm. The measured voltage and currents at the input and at the load resistance $\left(R_{L}\right)$, when inverter operates at tracked $25.5 \mathrm{kHz}$, are shown as oscilloscope screenshots in Figure 10.

\subsection{Scenario III}

In the third scenario, the sub-coil separation $\left(d_{s u b}\right)$, which is originally $60 \mathrm{~mm}$ for each coupler, is changed in secondary side coupler until the self-inductance of the secondary side coupler increases to $185 \mu \mathrm{H}$. Such a change results in switching the global power maximum from lower resonance frequency to the higher one as shown in Figure 11 (a). 


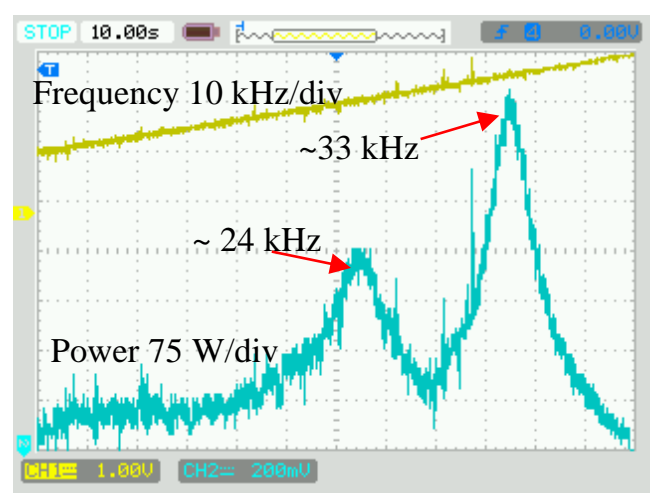

a) Sub-figure 1 .

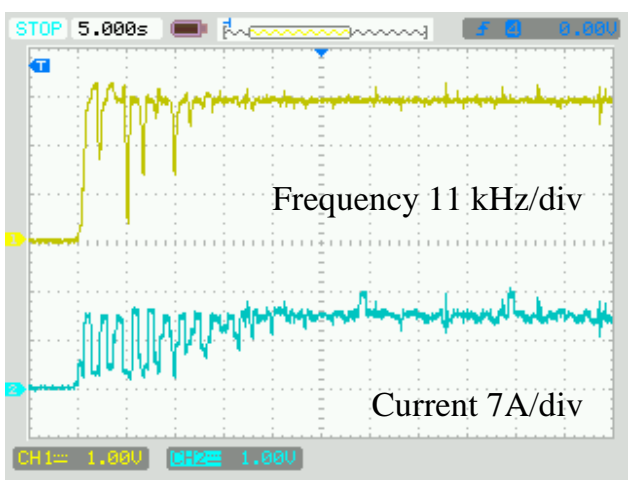

b) Sub-figure 2.

Figure 11. Oscilloscope screenshot for Scenario III for scanning for input power to the primary side resonant coupler and the inverter's switching frequency (a) and performance of PSO algorithm (b).

The data shown in Figure 11 (a) with cyan-colored line is the scanned input power and exhibits two peaks at approximately $24 \mathrm{kHz}$ and $33 \mathrm{kHz}$, respectively. The data with maize-colored line is the scanned frequency. As seen in Figure 11 (b), algorithm converges in less than 20 seconds and finds the $33 \mathrm{kHz}$ resonance frequency as the global maximum power point which agrees with Figure 11 (a). A major advantage of PSO algorithm is that it always converges to the global maximum and never stuck in a local maximum. To make a comparison, a PO algorithm is also run in the last scenario (scenario III). Figure 12 shows the oscilloscope screenshot of the PO algorithm's performance for tracking the frequency of maximum power.

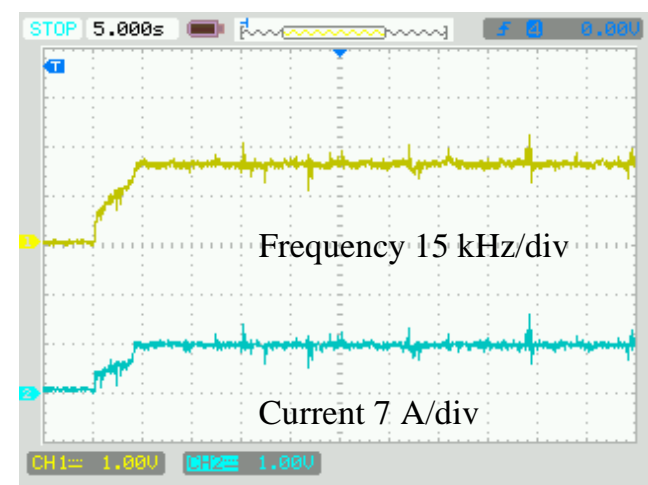

Figure 12. Performance of PO algorithm for scenario III

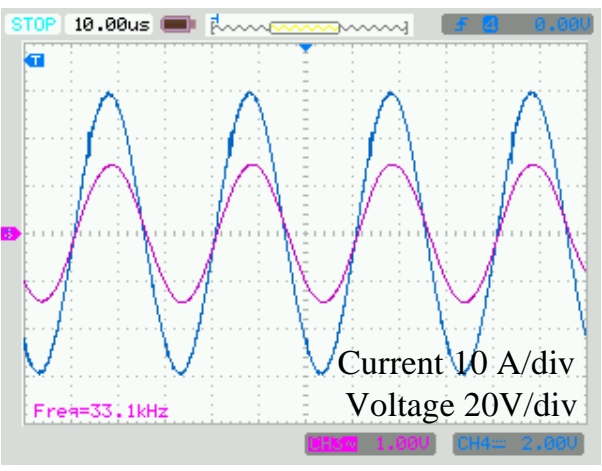

a) Sub-figure 1 .

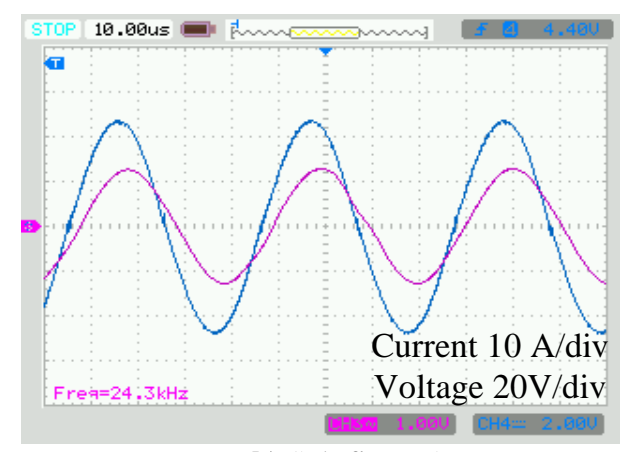

b) Sub-figure 2 .

Figure 13. Voltage and current waveforms at load resistance (RL) for scenario III (a) performance of PSO algorithm (b) performance of PO algorithm.

In Figure 12, within approximately ten seconds, the PO algorithm stucks in $24 \mathrm{kHz}$ which is not the maximum power point. Although the PO algorithm converges faster than the PSO algorithm, the converged frequency does not guarantee the maximum power point. Figure 13 shows the oscilloscope screenshots of measured voltage and current waveforms on the load resistance $\left(R_{L}\right)$ for both PSO and PO algorithms.

Performance data obtained for 3 different scenarios discussed in this article are summarized in Table 3. Comparison between PO and PSO algorithm has also been made for Scenario 3 to show incapability of PO algorithm tracking global maximum power point frequency . Although the PO algorithm converges faster than PSO algorihm, it stuck with the local maximum where input power $(300 \mathrm{~W})$ is much less than the global maximum $(500 \mathrm{~W})$ tracked by the PSO algorithm.

Table 3: Performance evaluation of algorithms

\begin{tabular}{|c|c|c|c|c|c|}
\hline \multirow[b]{2}{*}{ Scenario } & \multicolumn{3}{|c|}{ Frequency $(\mathrm{kHz})$} & \multirow{2}{*}{$\begin{array}{c}\text { Input } \\
\text { Power } \\
(\mathrm{W})\end{array}$} & \multirow[b]{2}{*}{$\begin{array}{l}\text { Conv. } \\
\text { Time (s) }\end{array}$} \\
\hline & $\begin{array}{r}\text { Loca } \\
\text { max }\end{array}$ & $\begin{array}{l}\text { obal } \\
\text { um }\end{array}$ & $\begin{array}{l}\text { Tracked } \\
\text { by algo. }\end{array}$ & & \\
\hline Scen & 33 & 24 & PSO:23,9 & PSO:405 & PS \\
\hline Scen & 31,5 & 5,5 & PSS & $\mathrm{PSC}$ & \\
\hline Sce & 24 & 33 & $\begin{array}{l}\text { PSO:33,1 } \\
\text { PO:24,3 }\end{array}$ & $\begin{array}{l}\text { PSO:525 } \\
\text { PO:300 }\end{array}$ & $\begin{array}{l}\text { PSO:15 } \\
\text { PO:5 }\end{array}$ \\
\hline
\end{tabular}




\section{Conclusion}

In this paper, a frequency tracking WPT system based on a PSO algorithm is presented. With the use of a PSO algorithm, inverter's frequency is tuned to a resonance frequency where maximum power is delivered to the load without sticking to a local maximum. An experimental WPT system is implemented under three different scenarios covering various misalignment and resonance conditions and compared with $\mathrm{PO}$ algorithm in misalignment scenario 3. The proposed PSO algorithm always converges to the resonance frequency of global maximum power in case frequency splitting. Furthermore, the proposed frequency tracking control method utilizes the current and voltage data at the primary side of the WPT system, making it a less complex single-sided controller. Therefore, no additional communication link between primary and secondary side is needed for maximizing the delivered power level. A potential future direction would be incorporating missing secondary side electronics such as a rectifier, a DC-DC converter, a battery management circuit and a battery to realize a complete WPT charger targeting a certain application such as an electric vehicle charger.

\section{References}

[1] Hui, S.Y. (2013). Planar wireless charging technology for portable electronic products and Qi. Proceeding of the IEEE, 101(6), 1290-1301.

[2] Wang, C.S., Stielau, O.H. \& Covic, G.A. (2005) Design considerations for a contactless electric vehicle battery charger. IEEE Transanctions on Industrial Electronics, 52( 5), 1308-1314.

[3] Imura, T., Okabe, H. \& Hori, Y. (2009). Basic experimental study on helical antennas of wireless power transfer for electric Vehicles by using magnetic resonant couplings. Proceedings of Vehicle Power and Propulsion Conference, Dearborn, IEEE, September, 936-940.

[4] Cho, I. K., Kim, S.M., Moon J.I., Yoon, J. H., Jeon, S.I. \& Choi, J. I. (2013). Wireless power transfer system for docent robot by using magnetic resonant coils. Proceedings of IEEE 5th International Symposium on Microwave, Antenna, Propagation and EMC Technologies for Wireless Communications (MAPE), Chendu, October, 251254.

[5] Deyle, T., \& Reynolds, M. (2008). Surface based wireless power transmission and bidirectional communication for autonomous robot swarms. Proceedings of IEEE International Conference on Robotics and Automation (ICRA), Pasedana CA, May, 1036-1041.

[6] Li, X., Tsui, C.Y., \& Ki, W.H. (2015). A $13.56 \mathrm{MHz}$ wireless power transfer system with reconfigurable resonant regulating rectifier and wireless power control for implantable medical devices. IEEE Journal of Solid-State Circuits, 50(4), 978-989. Apr.
[7] Walk, J., Weber, J., Soell, C., Weigel, R., Fischer, G., \& Ussmueller, T. (2014). Remote powered medical implants for telemonitoring. Proceeding of IEEE, 102(11), 1811-1832.

[8] Chaidee, E., Sangswang, A., Naetiladdanon, S. \& Mujjalinvimut, E. (2017). Maximum output power tracking for wireless power transfer system using impedance tuning. IECON 43rd Annual Conference of the IEEE Industrial Electronics Society, Beijing, October- November, 6961-6966.

[9] Luo, Y., Yang, Y., Chen, S. \& Wen, X. (2017). A frequency-tracking and impedance-matching combined system for robust wireless power transfer. International Journal of Antennas and Propagation. 2017,1-13.

[10] Barman, S.D., Reza, A.W., Kumar, N. \& Anowar, T.I. (2015). Two-side Impedance Matching for Maximum Wireless Power Transmission. IETE Journal of Research, 62(4), 532-539.

[11] Liu, N. \& Habetler, T.G. (2015). Design of a universal inductive charger for multiple electric vehicle models. IEEE Transactions on Power Electronics, 30(11), 6378-6390.

[12] Sis, S.A., Kilic, F. \& Sezen, S. (2019). Multi sub-coil flux pipe couplers and their use in a misalignmentadaptive wireless power transfer system. Journal of Electromagnetic Waves and Applications. 33(14), 1890-1904.

[13] Lin, Z., Wang, J., Fang, Z., Hu, M., Cai, C. \& Zhang, J. (2018). Accurate maximum power tracking of wireless power transfer system based on simulated annealing algorithm. IEEE Access. 6, 60881-60890.

[14] Hongbo, S. \& Shuxia, L. (2008). The comparison between genetic simulated annealing algorithm and antcolony optimization algorithm for ASP. 4th International Conference on Wireless Communications, Networking and Mobile Computing, Dalian, IEEE, October, 1-6.

[15] Abreu, R.L., Pimenta, T.C. \& Spadoti, D.H. (2017). Self-tuning capacitance for impedance matching in wireless power transfer devices. 29th International Conference on Microelectronics (ICM); Beirut, IEEE, December, 1-4.

[16] Jabri, I., Bouallegue, A. \& Ghodbane, F. (2017). Frequency and misalignment $P \& O$ controller for wireless battery charger. International Conference on Green Energy Conversion Systems (GECS), Hammamet, IEEE, March, 1-6.

[17] Li, Y., Zhang, C., Yang, Q., Li, J., Zhang, Y., Zhang, X. \& Xue, M. (2018). Improved ant colony algorithm for adaptive frequency tracking control in WPT system. IET Microwaves, Antennas and Propagation, 12(1), 23-28.

[18] Bai, J. \& Li. S. (2011). Improvement in Extension of Ant Colony Optimization and its appliance. 3rd International Conference on Advanced Computer Control, Harbin, IEEE, January, 557-560. 
[19] Ibrahim, M., Bernard, L., Pichon, L., Labour'e, E., Razek, A., Cayol, O., Ladas, D. \& Irving, J. (2016). Inductive Charger for Electric Vehicle: Advanced Modeling and Interoperability Analysis. IEEE Transactions on Power Electronics, 31(12), 80968114.

[20] Schuetz, M., Georgiadis, A., Collado, A. \& Fischer, G. (2015). A particle swarm optimizer for tuning a software-defined, highly configurable wireless power transfer platform. 2015 IEEE Wireless Power Transfer Conference (WPTC), Boulder, IEEE, May, $1-4$.

[21] Wang, M., Feng, J., Shi, Y., Shen, M. \& Jing, J. (2018). A Novel PSO-Based Transfer Efficiency Optimization Algorithm for Wireless Power Transfer. Progress in Electromagnetics Research. 85, 63-75.

[22] Covic, G.A., \& Boys, J.T. (2013). Inductive Power Transfer. Proceedin of IEEE, 101(6),1276-1289.

[23] Budhia, M., Covic, G. \& Boys, J. (2010). A new ipt magnetic coupler for electric vehicle charging systems. IECON 36th Annual Conference on IEEE Industrial Electronics Society, Glendale, November, 2487-2492.

[24] Siqi, L. and Mi, C.C. (2014). Wireless power transfer for electric vehicle applications. IEEE Journal of Emerging Selected Topics on Power Electronics. 3(1), 4-17.

[25] Heebl, Jason D., et al. "Comprehensive analysis and measurement of frequency-tuned and impedancetuned wireless non-radiative power-transfer systems." IEEE Antennas and Propagation Magazine 56.4 (2014): 44-60.

[26] Kermadi, M., Salam, Z., Ahmed, J. \& Berkouk, M. (2019). An effective hybrid maximum power point tracker of photovoltaic arrays for complex partial shading conditions. IEEE Transactions on Industrial Electronics. 66(9), 6990-7000.

[27] Ram, J.P., Pillai, D.S., Rajasekar, N. \& Strachan, S.M. (2019). Detection and identification of global maximum power point operation in solar $P V$ applications using a hybrid ELPSO-P\&O tracking technique. IEEE Journal of Emerging Selected Topics on Power Electronics, Early Access, 1-14.

[28] Soufi, Y., Bechouat, M. \& Kahla. S. (2018). Particle swarm optimization based maximum power point tracking algorithm for photovoltaic energy conversion system.15th International MultiConference on Systems, Signals \& Devices (SSD), Hammamet, IEEE, March, 773-779.
[29] Calvinho, G., Pombo, J., Mariano, S. \& Calado, M.R. (2018). Design and implementation of MPPT system based on PSO algorithm. International Conference on Intelligent Systems (IS), Funchal Madeira, IEEE, September, 733-738.

[30] Fahad, S., Mahdi, A.J., Tang, W.H., Huang, K. \& Liu, Y. (2018). Particle swarm optimization based DC-link voltage control for two stage grid connected PV inverter. International Conference on Power System Technology, Guangzhou, IEEE, November, 733-738.

[31] Efendi, M.Z., Setiawan, R.E., Murdianto, F.D., Mubarok, R.H., Windarko, N.A. \& Dirmawan, M. (2018). A Performance evaluation of MPPT using modified PSO algorithm for battery charge application. International Electronics Symposium on Engineering Technology and Applications (IESETA), Bali, IEEE, October, 8-12.

Fuat Kulıc received the B.S. and M.Sc. and Ph.D. degrees in electrical engineering from Kocaeli University, Kocaeli, Turkey, in 2001, 2003 and 2016, respectively. He is currently Assistant Professor with Ballkesir University in department of Mechatronics Engineering. His research interests include electrical machines, control theories, power electronics and renewable energy.

iD https://orcid.org/0000-0003-2502-3789

Serkan Sezen received the B.S., M.Sc. and Ph.D. degrees in Electrical Education from Kocaeli University, Kocaeli, Turkey, in 2003, 2006 and 2015 respectively. He is currently Assistant Professor at Department of Electric and Energy, Uzunçiftlik Nuh Çimento Vocational School, Kocaeli University. His research interests are renewable energy, power electronics, control theories and electrical machines.

(iD) http://orcid.org/0000-0001-7273-7376

Seyit Ahmet Sis received the B.S. degree in electronics engineering from the The Gebze Institute of Technology, Kocaeli, Turkey, in 2005, the M.S. degree in electrical engineering from The Syracuse University, Syracuse, NY, and the Ph.D. degree from The University of Michigan at Ann Arbor in 2014. Since July 2014, he has been with The Balikesir University as a faculty member in the Electrical and Electronics Engineering Department. He is also working as a Senior Researcher with a part-time appointment at TÜBİTAK-BILGEM since 2015. His current research interests include wireless power transfer systems, switchable and tunable microwave components and circuits, RF passive sensors and high efficiency power-amplifier design for wireless applications.

D http://orcid.org/0000-0002-3740-2391

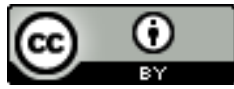


This work is licensed under a Creative Commons Attribution 4.0 International License. The authors retain ownership of the copyright for their article, but they allow anyone to download, reuse, reprint, modify, distribute, and/or copy articles in IJOCTA, so long as the original authors and source are credited. To see the complete license contents, please visit http://creativecommons.org/licenses/by/4.0/. 